\title{
Corrigendum to "Kaempferol Attenuates Myocardial Ischemic Injury via Inhibition of MAPK Signaling Pathway in Experimental Model of Myocardial Ischemia-Reperfusion Injury"
}

\author{
Kapil Suchal, ${ }^{1}$ Salma Malik, ${ }^{1}$ Nanda Gamad, ${ }^{1}$ Rajiv Kumar Malhotra, ${ }^{1}$ Sameer N. Goyal $\mathbb{D}^{2}{ }^{2}$ \\ Uma Chaudhary, ${ }^{3}$ Jagriti Bhatia $\left(\mathbb{1},{ }^{1}\right.$ Shreesh Ojha $\left(\mathbb{1},{ }^{4}\right.$ and Dharamvir Singh Arya $\left(\mathbb{1}^{1}\right.$ \\ ${ }^{1}$ Department of Pharmacology, Cardiovascular Research Laboratory, All India Institute of Medical Sciences, New Delhi 110029, India \\ ${ }^{2}$ Department of Pharmacology, R.C. Patel Institute of Pharmaceutical Education and Research, Shirpur, Maharashtra 425405, India \\ ${ }^{3}$ Department of Biomedical Science, Bhaskaracharya College of Applied Science, University of Delhi, Delhi 110075, India \\ ${ }^{4}$ Department of Pharmacology and Therapeutics, College of Medicine and Health Sciences, United Arab Emirates University, \\ P.O. Box 17666, Al Ain, Abu Dhabi, UAE
}

Correspondence should be addressed to Dharamvir Singh Arya; dsarya16@gmail.com

Received 27 May 2020; Accepted 28 May 2020; Published 18 June 2020

Copyright (C) 2020 Kapil Suchal et al. This is an open access article distributed under the Creative Commons Attribution License, which permits unrestricted use, distribution, and reproduction in any medium, provided the original work is properly cited.

In the article titled "Kaempferol Attenuates Myocardial Ischemic Injury via Inhibition of MAPK Signaling Pathway in Experimental Model of Myocardial Ischemia-Reperfusion Injury" [1], it was identified that the beta-actin panels in Figures 4(a), 4(b), and 4(c) were identical. With the agreement of the editor, a revised version of Figure 4 is being provided with the data from a repeat of the experiment. The authors apologize for this error in the original publication. The corrected version of figure 4 is shown as Figure 1. 

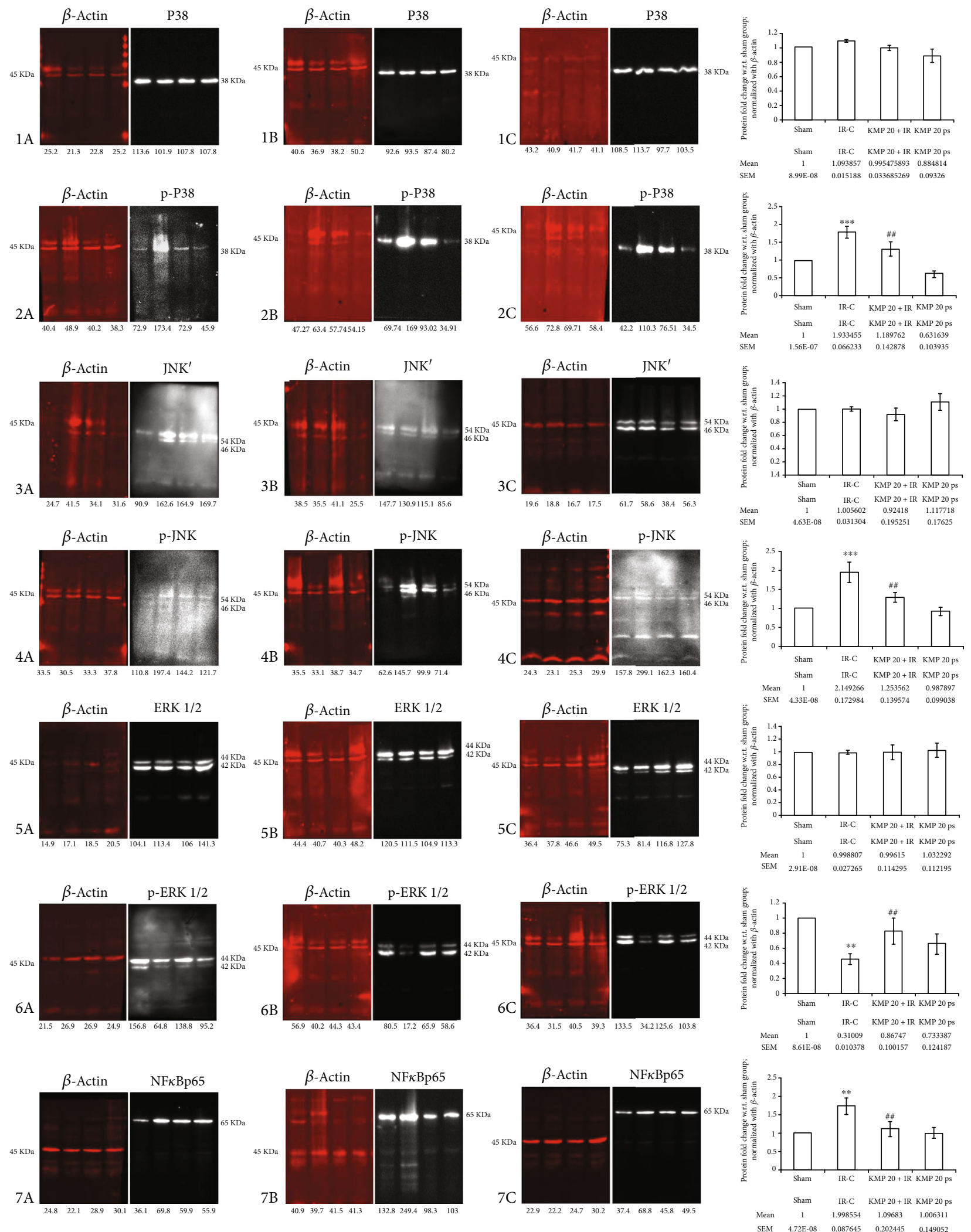

FIGURE 1: Effect of KMP on MAPKs protein expressions. (a) ERK1/ERK2, p-ERK1/ERK2; (b) JNK, p-JNK; (c) p38, p-p38; and (d) NF $\kappa$ Bp65. Data are expressed as normal intensity (\% control). All the values are expressed as mean \pm SEM; $n=3$ per group. ${ }^{* * *} p<0.001$ versus sham; ${ }^{\#} p<0.05 ;{ }^{\# \#} p<0.01$; and ${ }^{\# \#} p<0.001$ versus IR-control. 


\section{References}

[1] K. Suchal, S. Malik, N. Gamad et al., "Kaempferol Attenuates Myocardial Ischemic Injury via Inhibition of MAPK Signaling Pathway in Experimental Model of Myocardial IschemiaReperfusion Injury," Oxidative Medicine and Cellular Longevity, vol. 2016, Article ID 7580731, 2016. 